\title{
Eficácia dos coadjuvantes de higiene bucal utilizados na alimentação de cães
}

[Effectiveness of buccal hygiene coadjutant used in the dogs feeding]

\author{
A.C. Paiva ${ }^{1}$, F.M.O.B. Saad ${ }^{2}$, C.A.L. Leite $^{2}$, A. Duarte ${ }^{3}$, D.A.R. Pereira ${ }^{3}$, C.A.C. Jardim ${ }^{1}$ \\ ${ }^{1}$ Médico veterinário autônomo \\ ${ }^{2}$ Universidade Federal de Lavras - Lavras, MG \\ ${ }^{3}$ Total Alimentos - Três Corações - MG
}

\begin{abstract}
RESUMO
Avaliou-se a utilização de coadjuvantes na diminuição da placa bacteriana e formação do cálculo dentário em 16 cães. O delineamento experimental foi casualizado com quatro tratamentos $(\mathrm{T})$ e quatro repetições. Os tratamentos foram: T1- controle, T2- coadjuvante com ação mecânica, T3- coadjuvante com tripolifosfato de sódio e T4- coadjuvante com hexametafosfato de sódio. Após sete dias de adaptação, no dia anterior ao início dos tratamentos, os animais foram submetidos à remoção de cálculo dentário. $\mathrm{O}$ experimento teve duração de 21 dias e ao final realizaram-se as medições das placas bacterianas formadas com o uso de marcadores (fucsina). O coadjuvante somente com ação mecânica não foi efetivo em retardar o aparecimento da placa bacteriana. Os coadjuvantes com polifosfatos apresentaram uma ação efetiva e significativa na diminuição da formação do calculo dentário.
\end{abstract}

Palavras-chave: cão, tripolifosfato de sódio, hexametafosfato de sódio, cálculo dentário

\begin{abstract}
The use of coadjutants in the decrease of the bacterial plate and formation of the dental calculus was evaluated in 16 dogs. The experimental design was randomized with four treatments (T) and four repetitions. The treatments were the following: 1-control; 2-coadjutant 1 (one) with mechanical action; 3- coadjutant 2 (two) with tripolyphosphate of sodium and 4- coadjutant 3 (three) with hexametaphosphate of sodium. After seven days of adaptation, on the day previous to the beginning of the treatments, the animals were submitted to the removal of dental calculus and after twenty-one days of treatment a measurement of the bacterial plaque formed through the use of markers (fucsin). The coadjutant only with mechanical action was not effective in delaying the appearance of the bacterial plaque. The coadjutant containing polyphosphates presented an effective and significant action decreasing the formation of the dental calculus.
\end{abstract}

Keywords: dog, sodium tripolyphosphate, sodium hexametaphosphate, dental calculus

\section{INTRODUÇÃO}

Os animais de companhia estão em grande destaque, pois o ser humano busca, na relação com estes animais, aliviar uma parcela do estresse causado pela vida urbana (Borges et al., 2003). A posse desses animais tem-se convertido em um passatempo, e o trato correto dos mesmos reveste-se de grande interesse para os proprietários e para os profissionais que trabalham com esses animais (Case et al., 1998).

Embora a odontologia veterinária seja uma especialização relativamente nova, o acúmulo da

Recebido em 3 de novembro de 2005

Aceito em 20 de junho de 2007

Endereço para correspondência (corresponding address)

Rua Paraná, 20 - 37002-280 - Varginha, MG

E-mail: paivaalessandra@hotmail.com 
placa bacteriana é um dos problemas mais comuns que afeta animais de companhia, sendo reconhecida por mais de 70 anos.

Gioso (2003) relatou que a doença periodontal afeta $75 \%$ dos caninos entre quatro e oito anos de idade. A doença periodontal atinge as quatro estruturas do periodonto: gengiva, ligamento periodontal, cemento e osso alveolar. $\mathrm{O}$ fator determinante, etiológico, é a placa bacteriana, que se acumula sobre os tecidos bucais e dentes podendo levar à cárie ou causar inflamação na gengiva (Dillon, 1984; Penman e Harvey, 1993; Harvey e Emily,1993; Gioso, 2003).

A placa bacteriana ou placa dental é composta de bactérias em uma matriz de glicoproteínas salivares e polissacarídeos extracelulares. A matriz encontra-se firmemente aderida à superfície do dente (Barker et al., 1993).

Os sinais mais comuns associados à doença periodontal são a halitose, o cálculo dentário, a inflamação e o sangramento gengival, a anorexia e o conseqüente emagrecimento, o ptialismo, a dificuldade de mastigar e triturar os alimentos, a mobilidade e a migração dos dentes, a perda de osso alveolar, a retração gengival e as alterações comportamentais (Gioso, 1997; Cox et al., 2003). O maior risco na periodontopatia não é a perda dos dentes ou o desenvolvimento de infecções locais, pois as bactérias que se encontram na boca do animal podem alcançar a corrente sangüínea e então serem levadas para outros órgãos e causarem infecções graves como glomerulonefrite, endocardite, artrite, meningite e discoespondilite (Goldstein, 1990; Gioso, 1994; Domingues et al., 1999).

Vários estudos demonstraram que há redução na formação do cálculo dentário em cães alimentados com uma dieta regular seca, quando comparados aos alimentados com dieta enlatada (úmida). Entretanto, ainda não está esclarecido se esse efeito é devido à ação abrasiva suave da ração seca ou devido ao alimento enlatado aderir-se mais facilmente ao tecido da placa bacteriana (The impact..., 2004).

Segundo Gioso (1994), um novo acúmulo de cálculo normalmente ocorre entre três a seis meses após a remoção do cálculo dentário. Após o tratamento periodontal, esse novo acúmulo, se não forem tomadas medidas preventivas, ocorre de seis a 24 meses; e, a única maneira de se evitar o acúmulo de nova placa é a escovação, comprovada como eficaz, quando efetuada três vezes por semana, com sessões as mais duradouras possíveis. Como os animais precisam ser condicionados a tais procedimentos desde novos, a maioria dos proprietários prefere utilizar snacks ou tiras de couros na prevenção da formação do cálculo dentário (The impact..., 2004).

Nos últimos anos houve uma acentuada expansão da oferta de produtos destinados a facilitar os cuidados dentários domésticos para os proprietários e a ser mais toleráveis para os animais de estimação (Gioso, 2003). Os biscoitos anticálculos podem ser usados como coadjuvantes na prevenção da doença periodontal (Gioso, 1994). A estratégia padrão para evitar o cálculo é a raspagem mecânica para limpar os dentes. Isso foi basicamente alcançado modificando-se a textura e o tamanho do grânulo da ração, porém apenas atinge os dentes utilizados no ato da mastigação. Uma nova abordagem utiliza fontes minerais nutricionais que podem proporcionar benefícios dentários como a diminuição da formação da placa bacteriana (Cox et al., 2003).

Fontes nutricionais de fosfatos podem ser manipuladas durante a fabricação de rações para acentuar as propriedades físicas sem alterar as fórmulas de base ou o tamanho do grânulo. Os cristais de polifosfatos ajudam a prevenir a mineralização da placa, pois formam uma barreira física em sua superfície, onde permanecem até que o organismo os absorva como nutrientes fosforosos proporcionando, assim, benefício dentário prolongado. Os polifosfatos, ao serem liberados da ração, podem proporcionar benefícios às superfícies não envolvidas na mastigação e, também, às de contato como as gengivas. Cães alimentados com ração revestida de polifosfatos desenvolveram $55 \%$ menos cálculo que animais alimentados com ração não revestida (Cox et. al., 2003).

O hexametafosfato de sódio é um seqüestrante que forma complexos solúveis com uma variedade de produtos. Pesquisas realizadas com cães demonstraram que o uso de hexametafosfato de sódio acrescido a rações secas reduziu a formação de cálculo entre 50 a 80\% (Stookey et al., 1995; The impact..., 2004) e quando 
acrescido a snacks a redução foi de 46\% (Stookey et al., 1996).

Reconhecendo a importância e os benefícios da saúde bucal dos cães e a dificuldade de controle da higiene dentária, os objetivos deste experimento foram avaliar os efeitos de coadjuvantes de ação mecânica na higiene bucal e o uso do polifosfatos de sódio na diminuição da ocorrência de cálculo dentário. Correlacionar o pH salivar e profundidade do sulco gengival com o grau de ocorrência de cálculo dentário.

\section{MATERIAL E MÉTODOS}

O delineamento experimental foi inteiramente casualizado, com quatro tratamentos $(\mathrm{T})$ e quatro repetições. Utilizaram-se 16 cães da raça Foxhound Americano, machos e fêmeas, não castrados, com idade média de cinco anos e peso médio aproximado de 35 quilos. Os tratamentos avaliados foram: T1 - controle sem coadjuvante; T2 - com coadjuvante de ação mecânica; T3 com coadjuvante de ação mecânica e adição de tripolifosfato de sódio; T4 - com coadjuvante de ação mecânica e adição de hexametafosfato de sódio. Os coadjuvantes foram utilizados nas quantidades recomendadas pelo fabricante, de acordo com o peso médio do animal.

Após o período de sete dias para adaptação à dieta, no dia anterior ao início dos tratamentos, foram realizadas, com os animais sob anestesia, extrações dos cálculos dentários, com auxílio de ultra-som, curetas e polimento. Os animais foram tratados durante 21 dias, e ao final, também, com os animais sob anestesia, foram realizadas as medições dos acúmulos das placas bacterianas formadas.
A medição da placa bacteriana foi feita com o de uso de corante (fucsina), pelo método modificado de Stookey et al. (1996). A contagem numérica para cada tratamento foi obtida pela somatória dos índices de cobertura da placa bacteriana de cada dente e o total dividido pelo número de repetições, obtendo para cada dente de cada tratamento um único valor. $\mathrm{O}$ mesmo procedimento foi feito para a espessura, sulco dentário e $\mathrm{pH}$ por meio de sonda periodontal graduada em mm e fita de medição de $\mathrm{pH}$, respectivamente. As variáveis experimentais foram analisadas segundo o pacote SISVAR for Windows versão 4.6 (Furtado, 2003); a verificação de diferença significativa entre as variáveis, pelo teste $\mathrm{F}$; e a classificação das médias, pelo teste de Scott-Knott.

\section{RESULTADOS E DISCUSSÃO}

Nas Tab. 1, 2 e 3 estão descritos os índices médios da medição da cobertura, espessura e cobertura $\times$ espessura da placa bacteriana maxilar, respectivamente. Os índices médios de cobertura da placa bacteriana não apresentaram diferença $(\mathrm{P}>0,05)$ entre os tratamentos. Os resultados da medição da espessura não apresentaram diferença entre os tratamentos para os dentes caninos, pré-molar 2 e molar $(\mathrm{P}>0,05)$ porém, para os dentes pré-molar 3 e pré-molar 4 verificaram-se diferenças entre os tratamentos $(\mathrm{P}<0,05)$. T3 e T4 foram iguais entre si $(\mathrm{P}>0,05)$, mas superiores $(\mathrm{P}<0,05)$ a $\mathrm{T} 1$ e $\mathrm{T} 2$ os quais, por sua vez, foram iguais entre si. Comportamento idêntico foi observado, também, para cobertura $x$ espessura, em que, os tratamentos com os coadjuvantes que continham tripolifosfato e hexametafosfato de sódio foram superiores $(\mathrm{P}<0,05)$ aos tratamentos-controle e ao que utilizou apenas ação mecânica.

Tabela 1. Índices médios relativos à medição de cobertura da placa bacteriana dos dentes maxilares em cães submetidos a diferentes tratamentos $(\mathrm{T})$

\begin{tabular}{cccccc}
\hline T & Canino & Pré-molar 2 & Pré-molar 3 & Pré-molar 4 & Molar \\
\hline T1 & 0,75 & 2,75 & 3,00 & 4,00 & 3,50 \\
T2 & 0,25 & 2,75 & 3,50 & 4,00 & 4,00 \\
T3 & 0,25 & 2,00 & 2,50 & 3,75 & 3,50 \\
T4 & 0,75 & 2,50 & 3,25 & 4,00 & 3,75 \\
CV & 100 & 63,77 & 30,91 & 6,35 & 17,06 \\
\hline
\end{tabular}

T1=controle, $\mathrm{T} 2=$ coadjuvante de ação mecânica, T3=coadjuvante com tripolifosfato de sódio, T4=coadjuvante com hexametafosfato de sódio. Não houve diferença entre tratamentos $(\mathrm{P}>0,05)$. 
Tabela 2. Índices médios relativos à medição da espessura da placa bacteriana dos dentes maxilares em cães submetidos a diferentes tratamentos $(\mathrm{T})$

\begin{tabular}{cccccc}
\hline T & Canino & Pré-molar 2 & Pré-molar 3 & Pré-molar 4 & Molar \\
\hline T1 & $1,00 \mathrm{a}$ & $1,00 \mathrm{a}$ & $2,00 \mathrm{a}$ & $3,00 \mathrm{a}$ & $2,25 \mathrm{a}$ \\
$\mathrm{T} 2$ & $0,50 \mathrm{a}$ & $1,50 \mathrm{a}$ & $2,00 \mathrm{a}$ & $2,75 \mathrm{a}$ & $2,50 \mathrm{a}$ \\
$\mathrm{T} 3$ & $0,25 \mathrm{a}$ & $1,00 \mathrm{a}$ & $1,00 \mathrm{~b}$ & $2,00 \mathrm{~b}$ & $1,75 \mathrm{a}$ \\
T4 & $1,25 \mathrm{a}$ & $0,75 \mathrm{a}$ & $1,00 \mathrm{~b}$ & $2,00 \mathrm{~b}$ & $2,00 \mathrm{a}$ \\
CV & 112,22 & 35,94 & 0,17 & 10,26 & 28,82 \\
\hline
\end{tabular}

T1=controle, T2=coadjuvante de ação mecânica, T3=coadjuvante com tripolifosfato de sódio, T4=coadjuvante com hexametafosfato de sódio. Médias seguidas por letras diferentes na coluna diferem pelo teste de Scott-Knott $(\mathrm{P}<0,05)$.

Tabela 3. Índices médios relativos à medição da cobertura $\mathrm{x}$ espessura da placa bacteriana dos dentes maxilares em cães submetidos a diferentes tratamentos $(\mathrm{T})$

\begin{tabular}{cc}
\hline T & Cobertura $x$ espessura \\
\hline T1 & $5,95 \mathrm{a}$ \\
T2 & $6,65 \mathrm{a}$ \\
T3 & $3,70 \mathrm{~b}$ \\
T4 & $4,50 \mathrm{~b}$ \\
CV & 15,76 \\
\hline
\end{tabular}

T1=controle, T2=coadjuvante de ação mecânica, T3=coadjuvante com tripolifosfato de sódio, T4=coadjuvante com hexametafosfato de sódio. Médias seguidas por letras diferentes na coluna diferem pelo teste de Scott-Knott $(\mathrm{P}<0,05)$.

As diferenças observadas, entre os tratamentos, referentes à espessura da placa bacteriana (prémolar 3 e pré-molar 4) e à cobertura x espessura, com melhores resultados para os tratamentos com tripolifosfato de sódio e hexametafosfato de sódio, permitem inferir que nesses tratamentos, além da atividade mecânica na mastigação, houve, também, atividade química dos fosfatos de sódio, o que, provavelmente, foi responsável pela sua melhor eficiência. Segundo Cox et al. (2003), os cristais de polifosfatos ajudam a prevenir a mineralização da placa em cálculo formando uma barreira física em sua superfície. Aliado a esses efeitos, os polifosfatos, também, podem proporcionar benefícios para toda a boca ao serem liberados durante a mastigação.

O baixo desempenho do coadjuvante que apresenta apenas ação mecânica (T2) se deve, provavelmente, ao fato deste ter agido, somente nos dentes onde houve contato. A abrasão mecânica proveniente de rações duras e produtos de mastigação, como os biscoitos e os snacks, somente promoverá atrito nos pontos onde o alimento entra efetivamente em contato com a superfície do dente. Os dados encontrados neste experimento confirmam que resultados uniformes com coadjuvantes de ação mecânica não serão obtidos em todos os dentes e podem, particularmente, não trazer benefícios para animais com má oclusão. Além disso, a ação abrasiva física pode ocorrer apenas enquanto o animal está efetivamente mastigando o produto. Não há qualquer efeito continuado sobre o dente quando o produto é deglutido, entre as refeições e entre as etapas de mastigação. A eficácia, também, será diminuída em cães que tendem a deglutir com pouca ou nenhuma ação de mastigação (Cox et al., 2003). Stookey et al. (1996) relataram que o hexametafosfato de sódio reduz a formação do cálculo dentário, isolando ou formando complexo com o cálcio, dentro da placa bacteriana, que dessa forma é difundido junto à saliva.

A maior ocorrência da formação de tártaro ocorre nos dentes pré-molares 4 superiores e dentes vizinhos, pois próximos a eles desembocam os ductos das glândulas parótida e zigomática (Gioso, 2003). Ocorrência, também, verificada neste trabalho.

Experimentos realizados por Stookey et al. (1996) demonstraram que a utilização do hexametafosfato de sódio reduziu em $62,8 \%$ a formação do cálculo dentário quando comparados com biscoitos convencionais, o que vem a confirmar os resultados obtidos neste trabalho. A conclusão mais importante dos estudos realizados até o momento é que os biscoitos convencionais não possuem efeito benéfico significativo na limpeza dos dentes de caninos.

Os índices médios de medição da cobertura, espessura e cobertura $\times$ espessura mandibular da placa bacteriana encontram-se nas Tab. 4, 5 e 6, respectivamente. Não ocorreu diferença $(\mathrm{P}>0,05)$ entre os tratamentos, quando avaliada a cobertura mandibular da placa bacteriana. Os resultados da medição da espessura da placa bacteriana também não apresentaram diferenças $(\mathrm{P}>0,05)$. 
Eficácia dos coadjuvantes de higiene bucal...

Tabela 4. Índices médios relativos à medição da cobertura da placa bacteriana dos dentes mandibulares em cães submetidos a diferentes tratamentos $(\mathrm{T})$

\begin{tabular}{cccccc}
\hline T & Canino & Pré-molar 2 & Pré-molar 3 & Pré-molar 4 & Molar \\
\hline T1 & 2,25 & 3,50 & 3,75 & 3,50 & 4,00 \\
T2 & 1,00 & 3,50 & 4,00 & 4,00 & 3,75 \\
T3 & 0,50 & 3,25 & 2,75 & 3,25 & 4,00 \\
T4 & 1,50 & 3,75 & 4,00 & 2,50 & 3,50 \\
CV & 72,11 & 19,34 & 21,81 & 25,78 & 14,66 \\
\hline
\end{tabular}

T1=controle, T2=coadjuvante de ação mecânica, T3=coadjuvante com tripolifosfato de sódio, T4=coadjuvante com hexametafosfato de sódio. Não houve diferença entre tratamentos $(\mathrm{P}>0,05)$.

Tabela 5. Índices médios relativos à medição da espessura da placa bacteriana dos dentes mandibulares em cães submetidos a diferentes tratamentos $(\mathrm{T})$

\begin{tabular}{cccccc}
\hline T & Canino & Pré-molar 2 & Pré-molar 3 & Pré-molar 4 & Molar \\
\hline T1 & 1,00 & 1,50 & 1,75 & 2,00 & 2,75 \\
T2 & 1,00 & 1,25 & 1,75 & 1,75 & 2,75 \\
T3 & 0,50 & 1,00 & 1,25 & 1,50 & 2,5 \\
T4 & 1,75 & 1,00 & 1,25 & 1,50 & 2,25 \\
CV & 52,61 & 32,16 & 33,33 & 37,28 & 20,31 \\
\hline
\end{tabular}

T1=controle, T2=coadjuvante de ação mecânica, T3=coadjuvante com tripolifosfato de sódio, T4=coadjuvante com hexametafosfato de sódio. Não houve diferença entre tratamentos $(\mathrm{P}>0,05)$.

Tabela 6. Índices médios relativos à medição da cobertura $\mathrm{x}$ espessura da placa bacteriana dos dentes mandibulares em cães submetidos a diferentes tratamentos $(\mathrm{T})$

\begin{tabular}{cc}
\hline $\mathrm{T}$ & Cobertura $\mathrm{x}$ espessura \\
\hline $\mathrm{T} 1$ & $6,45 \mathrm{a}$ \\
$\mathrm{T} 2$ & $6,10 \mathrm{a}$ \\
$\mathrm{T} 3$ & $4,5 \mathrm{~b}$ \\
$\mathrm{~T} 4$ & $4,7 \mathrm{~b}$ \\
$\mathrm{CV}$ & 18,75 \\
\hline
\end{tabular}

T1=controle, T2=coadjuvante de ação mecânica, T3=coadjuvante com tripolifosfato de sódio, T4=coadjuvante com hexametafosfato de sódio. Médias seguidas por letras diferentes na coluna diferem pelo teste de Scott-Knott $(\mathrm{P}<0,05)$.

Não houve diferença entre os tratamentos aplicados, quando avaliadas a cobertura mandibular e a espessura da placa bacteriana $(\mathrm{P}>0,05)$.

Para a presença da placa bacteriana nos dentes mandibulares, T3 e T4 apresentaram melhores resultados $(\mathrm{P}<0,05)$ que $\mathrm{T} 1$ e $\mathrm{T} 2$, quando analisado o parâmetro cobertura $\times$ espessura. Para as variáveis individualmente não foram observadas diferenças $(\mathrm{P}>0,05)$.

$\mathrm{O}$ grau de acometimento da placa bacteriana e consequentemente do cálculo dentário que nada mais é que a placa mineralizada, não ocorre de maneira proporcional e bem distribuída em toda a boca. Alguns dentes têm mais tendência à deposição da placa e entre as arcadas, também, existem diferenças. Nos dentes maxilares sempre são encontradas as maiores deposições da placa e cálculo dentário e, são também os primeiros dentes a apresentarem sinais de deposição quando comparados aos mandibulares, isso está quase sempre relacionado com a proximidade com os ductos das glândulas salivares (Román, 1999 e Gioso, 2003).

Em animais com alta concentração de cálculo dentário, devido muitas vezes a um grande tempo de deposição, podem ser observados dentes da mandíbula afetados. Com isto pode-se inferir que com um maior tempo de experimento poderia ter havido diferença significativa para cobertura e espessura da placa bacteriana nos dentes mandibulares.

As medições da profundidade do sulco gengival e dos valores de $\mathrm{pH}$ não apresentaram diferenças entre os tratamentos. Foram encontrados valores médios do sulco gengival em torno de 1 a $2 \mathrm{~mm}$ para todos os dentes analisados, com exceção do canino, que apresentou uma média de $2,5 \mathrm{~mm}$ (Tab. 7 e 8). A profundidade normal nos caninos está em torno de $1 \mathrm{a} 2 \mathrm{~mm}$. Valores acima desses podem implicar em periodontite, com formação de bolsa. É comum o achado de bolsas com 5 a $7 \mathrm{~mm}$, em casos mais graves (Gioso, 2003). 
Tabela 7. Índices médios relativos à medição de sulco gengival dos dentes maxilares em cães submetidos a diferentes tratamentos $(\mathrm{T})$

\begin{tabular}{cccccc}
\hline T & Canino & Pré-molar 2 & Pré-molar 3 & Pré-molar4 & Molar \\
\hline T1 & 2,50 & 1,75 & 1,75 & 1,50 & 1,50 \\
T2 & 2,00 & 1,75 & 1,50 & 1,75 & 1,50 \\
T3 & 2,50 & 1,25 & 1,25 & 1,50 & 1,00 \\
T4 & 2,50 & 1,50 & 1,50 & 1,75 & 1,25 \\
CV & 27,18 & 56,19 & 36,00 & 41,66 & 47,94 \\
\hline
\end{tabular}

T1=controle, T2=coadjuvante de ação mecânica, T3=coadjuvante com tripolifosfato de sódio, T4=coadjuvante com hexametafosfato de sódio. Não houve diferença entre tratamentos $(\mathrm{P}>0,05)$.

Tabela 7. Índices médios relativos à medição de sulco gengival dos dentes maxilares em cães submetidos a diferentes tratamentos $(\mathrm{T})$

\begin{tabular}{cccccc}
\hline T & Canino & Pré-molar 2 & Pré-molar 3 & Pré-molar4 & Molar \\
\hline T1 & 2,50 & 1,75 & 1,75 & 1,50 & 1,50 \\
T2 & 2,00 & 1,75 & 1,50 & 1,75 & 1,50 \\
T3 & 2,50 & 1,25 & 1,25 & 1,50 & 1,00 \\
T4 & 2,50 & 1,50 & 1,50 & 1,75 & 1,25 \\
CV & 27,18 & 56,19 & 36,00 & 41,66 & 47,94 \\
\hline
\end{tabular}

$\mathrm{T} 1=$ controle, $\mathrm{T} 2=$ coadjuvante de ação mecânica, $\mathrm{T} 3=$ coadjuvante com tripolifosfato de sódio, $\mathrm{T} 4=$ coadjuvante com hexametafosfato de sódio. Não houve diferença entre tratamentos $(\mathrm{P}>0,05)$.

Tabela 8. Índices médios relativos à medição do sulco gengival dos dentes mandibulares em cães submetidos a diferentes tratamentos $(\mathrm{T})$

\begin{tabular}{cccccc}
\hline T & Canino & Pré-molar 2 & Pré-molar 3 & Pré-molar4 & Molar \\
\hline T1 & 2,50 & 1,75 & 1,75 & 1,50 & 1,50 \\
T2 & 2,00 & 1,75 & 1,50 & 1,75 & 1,50 \\
T3 & 2,50 & 1,25 & 1,25 & 1,50 & 1,00 \\
T4 & 2,50 & 1,50 & 1,50 & 1,75 & 1,25 \\
CV & 27,18 & 56,19 & 36,00 & 41,66 & 47,94
\end{tabular}

T1=controle, T2=coadjuvante de ação mecânica, T3=coadjuvante com tripolifosfato de sódio, T4=coadjuvante com hexametafosfato de sódio. Não houve diferença entre tratamentos $(\mathrm{P}>0,05)$.

Em relação ao pH bucal, não houve variação significativa nos valores médios encontrados, com dados médios que variam de 8,0 a 8,5 (Tab. 9). De acordo com a literatura consultada, a formação do cálculo dentário em cães está relacionada aos altos valores encontrados no $\mathrm{pH}$ bucal desses animais. Esse $\mathrm{pH}$ elevado irá prevenir a formação de cáries nos caninos, mas favorecerá a precipitação de fosfatos de cálcio, com possível formação de cálculo dentário.

Tabela 9. Valores médios relativos à medição de $\mathrm{pH}$ da boca de cães submetidos a diferentes tratamentos $(\mathrm{T})$

\begin{tabular}{cc}
\hline T & $\mathrm{pH}$ \\
\hline T1 & 8,5 \\
T2 & 8,5 \\
T3 & 8,0 \\
T4 & 8,0 \\
CV & 4,95 \\
\hline
\end{tabular}

T1=controle, T2=coadjuvante de ação mecânica, T3=coadjuvante com tripolifosfato de sódio, T4=coadjuvante com hexametafosfato de sódio. Não houve diferença entre tratamentos $(\mathrm{P}>0,05)$.

\section{CONCLUSÃO}

Baseado nos resultados obtidos neste trabalho pode-se concluir que os biscoitos somente com ação mecânica não se mostram efetivos em retardar o aparecimento da placa bacteriana, não sendo recomendados para sua prevenção. Os coadjuvantes bucais que contêm polifosfatos, sob a forma de tripolifosfato ou hexametafosfato de sódio, apresentam uma ação efetiva e significativa na diminuição da formação do cálculo dentário, e podem ser recomendados como uma alternativa à escovação.

\section{REFERÊNCIAS BIBLIOGRAFICAS}

BARKER, I.K.; VAN DREUMEL, A.A.; PLAMER, N. The Alimentary System. In: JUBB, K.U.F., KENNEDY, P.C., PALMER N. (Eds). Pathology of Domestic animals. 4.ed. London: Academic Press. 1993. v.2, p.1-317 
BORGES, F.M.O; SALGARELLO, R.M.; GURIAN, T.M. Recentes avanços na nutrição de cães e gatos. In: SIMPÓSIO SOBRE NUTRIÇÃO DE ANIMAIS DE ESTIMAÇÃO, 3., 2003, Campinas. Anais... Campinas: CBNA, 2003. p.21-60,

CASE, L.P.; CAREY, D.P.; HIRAKAWA, D.A. (Eds). Nutrição Canina e Felina. Lisboa: Ed.Harcourt Brace, 1998. 424p.

COX, E.R.; LEPINE, A.J.; CAREY, D.P. Influencias nutricionales en la salud dental del perro. Rev. Med. Vet. Buenos Aires, v.83, p.265272, 2003.

DILLON, R. A cavidade oral.In: KIRK, R.W. (Ed). Atualização Terapêutica Veterinária: Pequenos animais. 7.ed. São Paulo: Manole, 1984. p.952-975.

DOMINGUES, L.M.; ALESSI, A.C.; SCHOKEN-ITURRINO, L.S. Microbiota saprófita associada à doença periodontal em cães. Arq. Bras. Med. Vet. Zootec., v.51, p.329332, 1999

FURTADO, D.F. Produtos tecnológicos desenvolvidos. 2003. Disponível em $<$ http://www.dex.ufla.br/danielff/prog.htm>. Acessado em 27 fev. 2004.

GIOSO, M.A. Doença periodontal em cães e gatos. Clin. Vet., v.8, p.2428, 1997.

GIOSO, M.A. (Ed). Odontologia Veterinária para o clínico de pequenos animais. 5.ed. São Paulo: FMVZ- USP, 2003. 202p.
GIOSO, M.A. (Ed). Odontologia Veterinária: Pequenos Animais. 3.ed. São Paulo: FMVZUSP, 1994, 180p.

GOLDSTEIN, G.S. Geriatrics dentistry in dogs. Comp.Cont. Educ. Pract. Vet., v.12, p.951-960, 1990

HARVEY, C. E.; EMILY, P.P. Small Animal Dentistry. St Louis: Mosby - Year Book, 1993. p.413

PENMAN, S.; HARVEY, C. E. Manual of Small dendistry. Chetenhan: British Small animal Veterinary Association, 1993. p. 37.

ROMÁN, F.S. Atlas de Odontología de Pequenos Animais. São Paulo: Ed. Manole $1^{\text {a }}$ ed., 1999, 115-119 p.

STOOKEY, G.K., WARRING, J.M., MILLER L.L. et al. Hexametaphosphate- coated Snacks Biscuits Significantly reduces calculus formation in dogs. J. Vet. Dent. v.13, p.27-30, 1996.

STOOKEY, G.K., WARRING, J.M.; MILLER L. L. Sodium hexametaphosphate reduces calculus formation in dogs. Am. J. Vet. Res. v.56, p.913-918, 1995.

THE IMPACT OF THE DIET IN

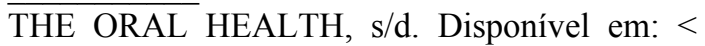
http://www.animalhealthcare.ca $>$. Acessado em: 02 mai. 2004.

YOULE, G. Periodontopatias ou Doença causada pelo tártaro em cães, $\mathrm{s} / \mathrm{d}$. Disponível em: $<\mathrm{http} / /$ mazuripurinamill.com/dentaguard.htm $>$. Acessado em: 10 mar. 2003 